\title{
National assessment of threatened species using sparse data: IUCN Red List
} classification of Anatidae in Iran

${ }^{2}$ Laboratory of Animal Ecology, Graduate School of Fisheries Science and Environmental Studies, Nagasaki University, Nagasaki, Japan

${ }^{3}$ Department of Environmental Sciences, Faculty of Environment and Energy, Science and Research Branch, Islamic Azad University, Tehran, Iran ${ }^{4}$ Centre for Biodiversity \& Environment Research, Department of Genetics, Evolution \& Environment, University College London, London, United Kingdom

\section{Authors:}
Elham Nourani $^{1,2}$, Mohammad Kaboli ${ }^{1 *}$, Mina Farhoodinia ${ }^{1,3}$, Ben Collen $^{4}$ ${ }^{1}$ Departnment of Environmental Sciences, Faculty of Natural Resources, University of Tehran, Tehran, Iran




\section{Abstract}

2 Classifying the status of threatened species using tools such as the IUCN Red List is a critical step for identifying at-risk species, and for conservation planning at global and sub-global levels. The requirement for data on population trends, geographic ranges and population sizes has proved challenging to carry out at the national level, especially in countries with unstructured and spatially limited monitoring schemes and limited conservation resources. In this study, we investigated the repeatability of risk assessments made under the IUCN Red List guidelines for assessment at the national level. Specifically, we assessed the national threat status of breeding and non-breeding populations of Anatidae in Iran using population and distribution data. The variable quality of these data led to uncertainties in decisionmaking. To evaluate the impact of these uncertainties on population trend estimates, we generated a range of alternative possible threat categories under three scenarios of population trend estimation. For the non-breeding populations, for which long-term population data were available, we were able to classify $93 \%$ of species, $72 \%$ of which were placed in threatened categories. For the breeding populations, $78 \%$ of the species were categorized as Data Deficient. Of those species in data sufficient categories, $67 \%$ were classified as threatened. We conclude that effective use of the IUCN categories and criteria at the national level is hampered in situations where monitoring schemes have a short history. Therefore, available data need to be complemented with some level of standardized data collection. We further make suggestions about efficient means of data collection in such cases and the importance of the use of modelling techniques prior to Red Listing and discuss the most useful IUCN criteria for threat categorization in such circumstances.

Keywords: Threat assessment, population trend, Area of Occupancy, Extent of Occurrence, African-Western Eurasian flyway, TRIM 
2 Red lists of threatened species are powerful tools for conservation. Identifying the relative 3 risk of extinction among groups of species, they have been used in conjunction with other 4 information for conservation planning and prioritization worldwide (Brito et al., 2010;

5 Farrier, Whelan \& Mooney, 2007; Mace \& Lande, 1991; Miller et al., 2006; Miller et al., 6 2007). The International Union for Conservation of Nature (IUCN) developed a set of criteria 7 to quantitatively assess the global threat status of species in 1994 (IUCN, 2001; Mace et al., 8 2008), allowing for consistent and repeatable risk assessments throughout taxonomic groups.

9 However, recognizing that most conflicts between humans and biodiversity, as well as most conservation efforts, take place at sub-global levels, countries around the world have developed their own schemes for compiling national and regional red lists (Avery et al., 1995; Master, 1991; Reed, 1992; Townsend et al., 2008; Warren et al., 1997). Doing so provides a metric with which to assess the fulfillment of requirements of Convention on 14 Biological Diversity (CBD) on monitoring biodiversity within their countries (Secretariat of the Convention on Biological Diversity, 2005). Such assessment schemes vary greatly in the factors that they consider as surrogates of extinction risk, as well as in defining and scoring these factors (De Grammont \& Cuarón, 2006). These differences impede comparisons among lists of threatened species produced in different countries and consolidating them for higher scale conservation planning is consequently unfeasible (Miller et al., 2007; Milner-Gulland et al., 2006; Zamin et al., 2010). To tackle this challenge and provide a common method for producing national red lists, IUCN published its Guidelines for application of IUCN Red List criteria at regional levels (hereafter the Regional Guidelines) in 2003 (Gärdenfors et al., 2001; IUCN, 2003). 
1 An objective assessment based on IUCN criteria, both at global and sub-global levels,

2 requires thorough knowledge of species being assessed, specifically on population size, rate of decline, geographic distribution, and threats (IUCN, 2001). Attempts at applying IUCN criteria at regional and national levels have mostly taken place in circumstances where the necessary data was either mostly available from ongoing comprehensive monitoring schemes, resources were available to make detailed surveys in areas where additional data was needed (Eaton et al., 2005; Miller et al., 2006; Milner-Gulland et al., 2006; Stojanović et al., 2013), or data collected by volunteers could be used (Fox et al., 2011; Maes et al., 2012). The situation in most regions of the world is less promising when it comes to threat assessment as not many countries collect structured data for a wide range of species (Maes et al., 2015; Moraes et al., 2014; Nascimbene, Nimis \& Ravera, 2013; Rankou et al., 2015). Natural history studies and biodiversity monitoring programmes in many countries have a relatively short history; considering that the aim of most red listing methods is to identify declines, this proves to be very challenging when it comes to quantifying extinction risk. Knowledge of the extent to which disparate data can be brought together to provide informative national species assessments could therefore be of great value to facilitating the take up of national red lists.

Natural history studies in Iran date back three centuries (Anderson, 1999). However, wildlife species are understudied in much of their range in the country, which hampers quantitative assessments of extinction risk. The current system for classifying threat status of wildlife in Iran consists of three categories of endangered, protected, and unprotected. The list that was compiled in 1999 by the Department of Environment of Iran (DOE) based on this scheme serves as the only source for determining national extinction risk and conservation status of species. Although this list has legal status, the criteria that have led to its establishment are not clearly defined by the DOE and classifications are difficult to update. This list has proven to be impractical for conservation planning and the need for a rigorous national red list that 
1 would provide a representation of species statuses is strongly felt both for setting

2 conservation priorities at the national level, and to provide critical information for regional

3 and global conservation projects.

4 In this study, we investigate the extent to which the IUCN categories and criteria, along with

5 the Regional Guidelines, are applicable for national Red Listing in the absence of long-term

6 structured data sources. We applied the IUCN categories and criteria to Anatidae (ducks,

7 geese, and swans) species in Iran to evaluate whether with current amount of data available,

8 this method is feasible for producing national Red Lists. We use Anatidae as a test group,

9 indicative of whether future efforts to produce a national Red List for other bird orders and

10 other vertebrate groups could be feasible for Iran, but also characteristic of the type of data

11 available for national red listing in other countries (i.e. periodic site level census data of

12 limited geographic scope, with idiosyncratic data gaps). This group are included in the annual waterbird censuses carried out by DOE as a contribution to International Waterbird Census schemes coordinated by Wetlands International in more than 100 countries. We provide details of the principal sources of uncertainty that we encountered during the process of calculating trends, and detail a framework of our decision-making under uncertainty, such as testing the A criterion under different scenarios to deal with missing data. We further provide insights about how this method of risk assessment can be used effectively for compiling national Red Lists in such circumstances. 
1 Thirty-five species of Anatidae have been recorded in Iran, six of which are considered either

2 as vagrants or very rare (Kaboli et al., 2012; Khaleghizadeh et al., 2011) and were therefore excluded from our study. Of the 29 species that we considered for national Red List assessment, 15 only occur as non-breeding migrants while the other 14 have both breeding and non-breeding populations within the country (Kaboli et al., 2012). We assessed breeding and non-breeding populations separately, as suggested by the Regional Guidelines (IUCN, 2003).

\section{Data collection}

We collected data on population size over time from the databases of DOE. This database includes results of the annual mid-winter waterbird censuses, initiated by DOE in 1966/1967 as a part of the African-Eurasian Waterbird Census scheme coordinated by Wildfowl Research Bureau (now Wetlands International) (Scott, 2010). DOE carries out surveys annually in mid-January all over Iran, counting waterbirds at important wetland sites throughout the country. The number of sites covered by this scheme has increased over time, due to identification of important natural or man-made waterbodies as well as improved accessibility, larger number of personnel and better equipment. Because this scheme only monitors populations of waterbirds in the winter, population size data were restricted to nonbreeding populations. To our knowledge, no other source of population size exists for this group of birds in Iran

Data on geographic range came from distribution maps of the Atlas of Birds of Iran (Kaboli et al., 2012), with a grid size of $25 \mathrm{~km} \times 25 \mathrm{~km}$. These maps were originally produced by collecting records of species occurrences throughout the country from the literature and expert knowledge, since the 1970s. Nourani, Kaboli \& Collen (2014) was consulted for species-specific threats affecting Anatidae in Iran. 
2 In this step, the IUCN Red List Categories (IUCN, 2001) were applied unaltered to Anatidae

3 species. Each species was assessed against as many of the criteria as the available data

4 allowed. In cases where assessment using different criteria resulted in alternative categories

5 for one species, the highest threat category was used. Assessments were done separately for

6 breeding and non-breeding populations.

$7 \quad$ Criterion A: Population trends

8 We calculated population trends for non-breeding populations over a period of three 9 generations or 10 years, whichever was longer. For each species, generation lengths were 10 collated from Birdlife International (2004) (see Supplementary Material). For breeding populations, no population trend was calculated.

Waterbird census data retrieved from the DOE database contained a large number of missing site-year combinations. In order to account for the uncertainty in the nature of the missing values, i.e. whether they represented no observation of a species at a specific time and location or whether the species was not counted or misidentified, we estimated population trends in three different scenarios to represent alternative ways of accounting for these missing data (Fig. 1).

For all three scenarios, we started by removing sites that included no counts (all missing values; e.g. site 1 in Fig. 1). This treatment resulted in time series of census data with an average of $80 \%$ years missing values for each species (see Supplementary Material for dataset specifications). In the "All Data" scenario, we used the whole time series for each species, and simply allowed the model (a log-linear Poisson regression, see below) to estimate the trend over data gaps, making no assumption about the nature of the missing years. In the "Assume Zero" scenario, we assumed that missing values corresponded to the 
1 absence of the species in a specific location and time, and therefore assumed missing values

2 equated to a zero count. In the "Remove Sites" scenario, we not only removed sites that

3 included only one count for the period of interest (e.g. site 3 in Fig. 1), but also removed any

4 site in which the difference between counts in any two subsequent years was greater than one

5 order of magnitude (an arbitrary change value selected to discount time series showing

6 biologically unrealistic trends; e.g. site 4 in Fig. 1).

7

\begin{tabular}{ccc} 
Site & Year & $\begin{array}{c}\text { Number of } \\
\text { observations }\end{array}$ \\
\hline 1 & 2009 & $?$ \\
1 & 2010 & $?$ \\
1 & 2011 & $?$ \\
1 & 2012 & $?$ \\
2 & 2009 & 22 \\
2 & 2010 & 20 \\
2 & 2011 & $?$ \\
2 & 2012 & 19 \\
3 & 2009 & $?$ \\
3 & 2010 & $?$ \\
3 & 2011 & 35 \\
3 & 2012 & $?$ \\
4 & 2009 & 54 \\
4 & 2010 & 5 \\
4 & 2011 & $?$ \\
4 & 2012 & $?$ \\
5 & 2009 & 23 \\
5 & 2010 & 22 \\
5 & 2011 & 20 \\
5 & 2012 & 20 \\
\hline & &
\end{tabular}
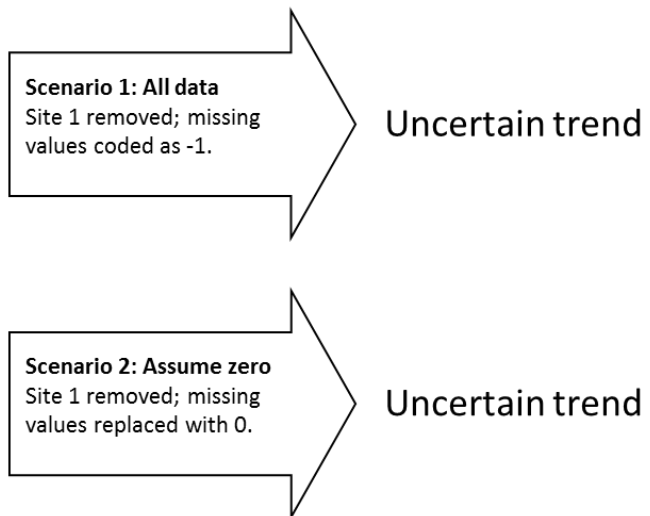

Uncertain trend

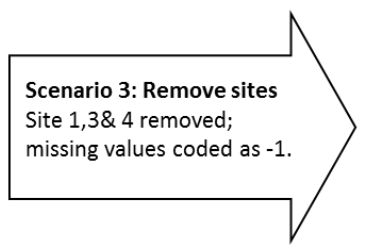

Moderate decline

Fig. 1 A hypothetical time series for a species in five sites, with three different scenarios applied. Missing values are shown with question marks in the table. Each arrow shows details of application of one scenario and points to the outcome of population trend analysis using log-linear Poisson regression in TRIM software. Note that missing values are coded as -1 when using TRIM.

We implemented log-linear Poisson regression models, which are widely used to analyse count data of the type collected for avian site census (Gregory et al., 2005; Van Strien et al., 2004). We used the software TRIM (Trends and Indices for Monitoring data) ver. 3.53 (Pannkoek \& van Strien, 2005) to calculate the percentage change in population size over time. We modelled population trends from site-based count data by considering expected counts in a given site and year as a function of quantities of each site and each year. Missing 
1 values were imputed using log-linear regression and incorporated into the model. We

2 excluded years that contained zero observations at the beginning and/or end of the analyzed

3 period for all three scenarios, and calculated trends using the linear trend model setting of

4 TRIM allowing as many change points as possible (Pannkoek \& van Strien, 2005). We

5 obtained a value for the average slope (i.e. multiplicative slope) of population trend model for

6 the years analysed. This slope was then classified into one of the six trend categories using

7 the classification approach detailed in Pannkoek \& van Strien (2005): Strong increase

8 (increase significantly more than 5\% per year), Moderate increase (significant increase, but

9 not significantly more than 5\% per year), Stable (no significant increase or decline; certain to

10 be less than 5\% per year), Uncertain (no significant increase or decline; not certain to be less than 5\% per year), Moderate decline (significant decline, but not significantly more than 5\% per year), and Steep decline (decline significantly more than 5\% per year). We then used these values to calculate the percentage of change in population size during the period of interest as follows:

$T t=\left(S^{(t-1)}-1\right) 100$

where $T$ is the long-term trend of change in population size after $t$ years and $S$ is the multiplicative slope of the regression model (see Pannkoek \& van Strien, 2005 for details on methodology).

Criterion B: Geographic range

Extent of occurrence (EOO) were estimated for assessment against sub-criteria B2, (IUCN, 2001). Values of EOO can be calculated using various methods such as alpha-hull and minimum convex polygon (MCP). Although IUCN guidelines (IUCN, 2011) allow for the calculation of EOO for separate subpopulations, i.e. exclusion of unsuitable habitats within the EOO, Joppa et al. (2016) recently recommended that calculating the EOO using an MCP 
1 would provide more consistency among Red List assessments and is more in line with the

2 underlying concept of EOO- a metric reflecting the spatial spread of risk from threats across

3 the species range (Collen et al., 2016). Moreover, our study species are highly mobile and

4 distinct subpopulations could not be defined for the wintering populations. We therefore

5 calculated EOOs by generating MCPs separately for wintering and breeding populations of

6 each species. We did not have sufficient data to calculate area of occupancy (AOO).

7 To be classified as threatened under criterion B, in addition to having EOO or AOO smaller 8 than the threshold values, a population must meet two of three sub-criteria: being severely

9 fragmented or having small number of locations, facing a continuing decline in population 10 size or geographic range, or undergoing extreme fluctuations (IUCN, 2001). We did not 11 consider any population of Anatidae to be isolated and severely fragmented. Number of 12 locations was calculated for wintering populations of Anatidae for which hunting was the main threat (Nourani et al., 2014), but we could not quantify the extent of other major threats. For the remaining two sub-criteria, we were only able to detect declines or fluctuations in population size, since due to a lack of quantitative data from the past, no trends could be calculated for EOO.

Criteria C and D: Population size

Although different in purpose, both criterion $\mathrm{C}$ and criterion $\mathrm{D}$ are based on the number of mature individuals. We estimated this using annual mid-winter waterbird census reports from 2012, the latest available survey data at the time of this study. We applied a ratio of 1:3 $(66.67 \%)$ to convert the number of wintering individuals to the number of mature individuals following Wetlands International (2012). 
1 In common with the vast majority of species assessed using IUCN Red List criteria, the

2 paucity of quantitative data on biological and ecological traits as well as scope and severity of

3 threats to Anatidae in Iran meant it was not possible to carry out Population Viability 4 Analyses. In fact, just six of the 79,837 species assessed on the global Red List have been

5 classified as threatened under criterion E (Collen et al., 2016).

\section{Application of IUCN Regional Guidelines: Second stage}

7 In the second stage, we adjusted the classification obtained in stage 1 based on the status of 8 conspecific populations outside the country. Depending on whether the outside populations 9 could pose a rescue effect on the risk of extinction of the national population, a downgrade, an upgrade or no change was applied to the categories (IUCN, 2003). We extracted data regarding the status of each Anatidae population at the corresponding flyway (Scott \& Rose, 1996), from databases of Wetlands International (http://wpe.wetlands.org).

\section{Results}

\section{Non-breeding populations}

16 The three scenarios of population trend estimation resulted in the same national classification 17 for $15(52 \%)$ species, two of which were classified as DD (Table 1). One species, marbled teal (Marmaronetta angustirostris), was classified as DD under the All Data and Assume Zero scenarios where the low quality of data due to infrequent counts led to an "Uncertain" population trend classification, while in the Remove Sites scenario, the trend calculated resulted in a CR classification. For the other 14 species however, classifications from trend estimation under the three scenarios was more variable (Table 1 and Supplementary 
1 Material). The second stage of the national assessment did not lead to any up- or down2 listing for the non-breeding populations.

3 The All Data and Assume Zero scenarios led to a high percentage of species classified in 4 threatened categories ( $80 \%$ and $86 \%$, respectively), with the Assume Zero scenario yielding a 5 higher frequency of the CR category (Fig. 2). The Remove Sites scenario resulted in a more 6 moderate categorization, assigning $72 \%$ of species to the threatened categories. In all 7 scenarios, categorizations were exclusively based on criteria A and D (Table 1). 


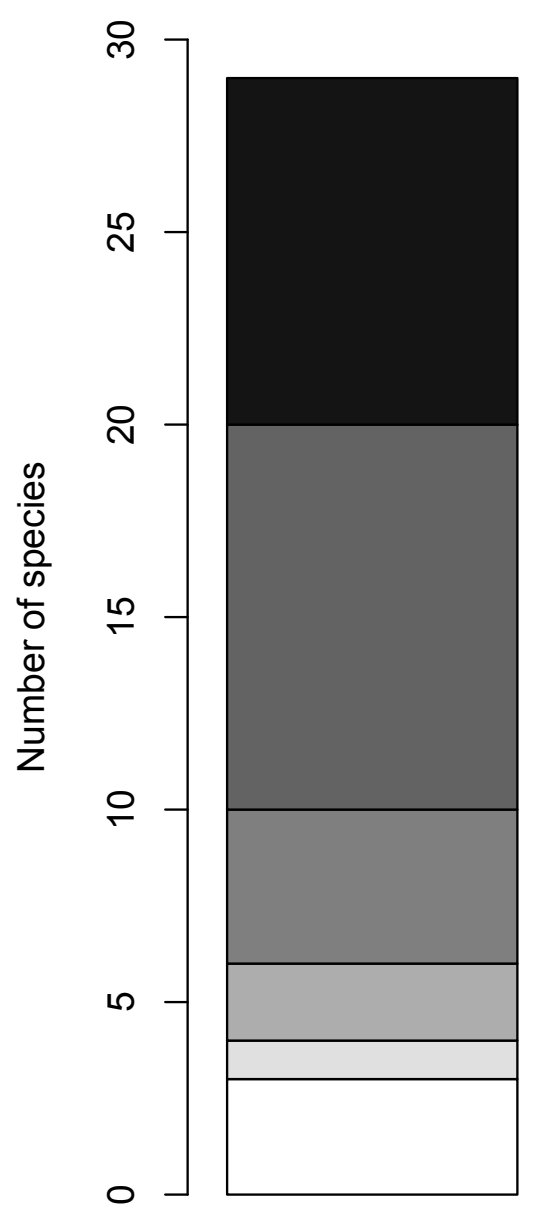

All.Data

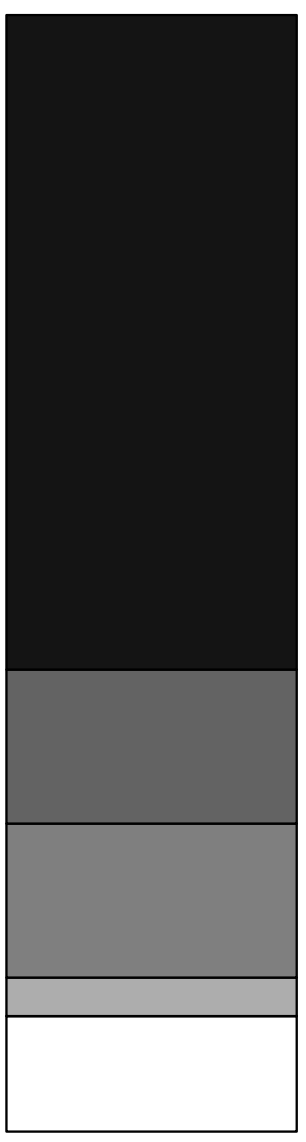

Assume.Zero

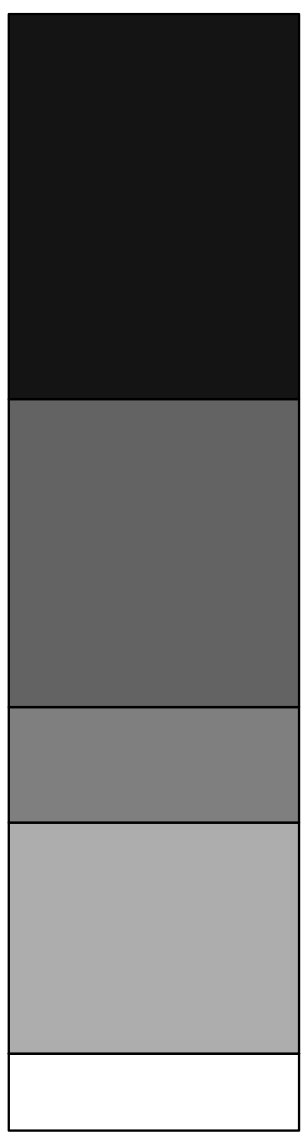

Remove.Sites

\section{Scenarios}

2 Fig. 2 Distribution of categories assigned to Anatidae species at the national level based on three different scenarios of population trend estimation for 10 years or three generations, whichever was longer. All Data Scenario: trends based on the whole dataset with inclusion of all missing values; Assume Zero Scenario: trends based on missing values treated as absences; Remove Sites Scenario: trends calculated based on sites with consistent data over the estimation period. 
2 Table 1 National Red List categories and criteria for non-breeding and breeding populations of Anatidae in Iran. For non-

3 breeding populations, categorization was based on three scenarios of population trend estimation. Categorization based on

4 the third scenario was considered the best representation of the status of these species at the national level. $\mathrm{A}^{\circ}$ sign indicates categories that were up- or down-graded in the second stage of assessment.

\begin{tabular}{|c|c|c|c|c|}
\hline \multicolumn{5}{|c|}{ Non-breeding populations } \\
\hline \multirow[t]{2}{*}{ Species } & \multirow{2}{*}{$\begin{array}{l}\text { All Data } \\
\text { Scenario }\end{array}$} & \multirow{2}{*}{$\begin{array}{c}\text { Assume Zero } \\
\text { Scenario }\end{array}$} & \multirow{2}{*}{$\begin{array}{c}\text { Remove Sites } \\
\text { Scenario }\end{array}$} & \\
\hline & & & & \\
\hline Cygnus olor & VU D1 & VU A2 b; D1 & CR A2 b & - \\
\hline C. cygnus & $\mathrm{CR}$ A2 b & CR A2 b & CR A2 b & - \\
\hline C. bewickii & EN D & CR A2 b & CR A2 b & - \\
\hline Anser anser & NT & $\mathrm{EN} \mathrm{A} 2 \mathrm{~b}$ & $\mathrm{CR}$ A2 b & $\mathrm{NT}^{\circ}$ \\
\hline A. fabalis & $\mathrm{DD}$ & $\mathrm{DD}$ & $\mathrm{DD}$ & - \\
\hline A. albifrons & $\mathrm{CR}$ A2 b & $\mathrm{EN} \mathrm{C1}$ & NT & - \\
\hline A. erythropus & CR D & CR D & CR D & - \\
\hline Branta ruficollis & CR D & CR D & CR D & - \\
\hline Tadorna tadorna & $\mathrm{CR}$ A2 b & CR A2 b & NT & $\mathrm{DD}$ \\
\hline T. ferruginea & $\mathrm{CR}$ A2 b & $\mathrm{CR}$ A2 b & $\mathrm{CR}$ A2 b & DD \\
\hline Anas penelope & $\mathrm{EN} \mathrm{A} 2 \mathrm{~b}$ & $\mathrm{CR}$ A2 b & NT & - \\
\hline A. strepera & EN A2 b & $\mathrm{CR}$ A2 b & NT & $\mathrm{DD}$ \\
\hline A. crecca & $\mathrm{EN} \mathrm{A} 2 \mathrm{~b}$ & CR A2 b & EN A2 b & DD \\
\hline A. platyrhynchos & $\mathrm{LC}$ & $\mathrm{CR}$ A $2 \mathrm{~b}$ & EN A2 b & DD \\
\hline A. acuta & $\mathrm{EN} \mathrm{A} 2 \mathrm{~b}$ & $\mathrm{CR}$ A2 b & NT & - \\
\hline A. querquedula & EN D & EN D & EN D & $\mathrm{EN}^{\circ} \mathrm{B} 1 \mathrm{a}(\mathrm{iii})$ \\
\hline A. clypeata & $\mathrm{EN} \mathrm{A} 2 \mathrm{~b}$ & $\mathrm{CR}$ A2 b & EN A $2 b$ & $\mathrm{CR}^{\circ} \mathrm{B} 1 \mathrm{ab}(\mathrm{iii})$ \\
\hline Marmaronetta angustirostris & DD & $\mathrm{DD}$ & $\mathrm{CR}$ A $2 \mathrm{~b}$ & $\mathrm{DD}$ \\
\hline Netta rufina & CR D & CR D & CR D & $\mathrm{DD}$ \\
\hline Aythya ferina & $\mathrm{CR}$ A2 b & CR A2 b & EN A2 b & $\mathrm{DD}$ \\
\hline A. nyroca & VU D1 & VU D1 & VU D1 & DD \\
\hline A. fuligula & NT & NT & NT & DD \\
\hline A. marila & $\mathrm{EN} \mathrm{A} 2 \mathrm{~b}$ & $\mathrm{CR}$ A2 b & $\mathrm{EN} \mathrm{A} 2 \mathrm{~b}$ & - \\
\hline
\end{tabular}




\begin{tabular}{lcccc} 
Clangula hyemalis & DD & DD & DD & - \\
Bucephala clangula & VU D1 & VU D1 & VU D1 \\
Mergellus albellus & VU D1 & VU D1 & VU D1 \\
Mergus serrator & CR D & CR D & CR D & - \\
M. merganser & EN D & EN D & EN D & - \\
Oxyura leucocephala & EN D & CR A2 b & EN D & DD \\
\hline
\end{tabular}

1

\section{$2 \quad$ Breeding populations}

3 Due to the lack of population estimates for breeding Anatidae in Iran, 11 species $(78 \%$ of our 4 total) were classified as DD. Although EOO estimates were available for all but one species, 5 data were typically lacking for two of the three qualifiers on the second part of the criterion.

6 For tufted duck (Aythya fuligula) only two occurrence points were recorded and therefore a 7 minimum convex polygon could not be created. Three assessments led to successful 8 classifications, two of which resulted in threatened categories based on criterion B1.

\section{Discussion}

Opportunistically collected data regarding population size, geographic distribution, and threats, led to reasonably consistent classification of breeding and non-breeding populations of Anatidae in Iran. We found though that the way in which uncertain data were treated could have an impact on the classification of species. Our study is likely to be typical of national data collection networks for vertebrates, where inconsistent, unstructured data collection, and a need to estimate change based on uncertain and opportunistically collected census data, abounds. While analysing the data that we were able to gather, both population size and geographic range, required an investment of time, these data proved appropriate for use in 
1 constructing national Red List assessments. Our assessment of 29 non-breeding and 14

2 breeding populations of Anatidae in Iran resulted in successful classification of the relative extinction risk of $89 \%$ of wintering populations under the All Data and Assume Zero population trend scenarios and $93 \%$ under the Remove Sites scenario. We were able to classify only $21 \%$ of the breeding species; the remaining species were classified as Data Deficient. We were more successful in assessing non-breeding species because long-term monitoring of their population size was available, data not typically collected in Iran for breeding populations.

The relatively simple rule-set for estimating population trend for the IUCN Red List belies a set of rather more complicated decisions on how to treat data. In our study, the large number of missing values in the population data (about 80\%; Supplementary Material), lack of a uniform representation of important wetlands in the monitoring scheme, and the large number of unidentified individuals in the census efforts were the main sources of uncertainty. As suggested by Akçakaya et al. (2000), we accounted for the uncertainty in the data by considering alternative classifications for each species, based on a set of assumptions about the underlying population dataset. In the Assume Zero scenario, we considered the possibility that missing values might represent instances of species' absence in a given site and time. However, consultation with DOE Ornithology Unit suggested that missing values in the database were mostly caused by lack of experienced and trained personnel, lack of equipment and vehicles and inaccessibility to sites due to harsh weather conditions. This indicated that not all missing values corresponded to the absence of individuals, but rather resulted from failure of recording for various reasons. Therefore, in the Remove Sites scenario, which was the most conservative treatment of the data, we retained the missing values, but this time only included sites that had a more consistent monitoring throughout the years. This data treatment and trend estimation yielded more moderate results than the previous two scenarios, though 
1 making the additional assumption that the lower number of sites monitored are representative

2 of all the sites that the species is present in. This scenario also led to national classification of M. angustirostris as Critically Endangered, DD under the previous two scenarios (a globally Vulnerable species). While it is the most conservative treatment of the data, we considered the results of the third scenario as the most acceptable categories for Anatidae in Iran, both because it resulted in the largest number of species being classified and also that the resulting distribution of categories were felt to be the most realistic. It must be noted, however, that this decision was made subjectively based on our experience with the species and might not represent the best decision under all circumstances. In such situations, it is wiser to consider the resulting categories as hypotheses based on the best available data and expert knowledge, which need to be tested when higher quality data is collected (e.g. Bennun, Njoroge \& Pomeroy, 2000).

Our assessments under criterion A were only based on sub-criterion A2 since declines are not known to have ceased and the reasons for decline are neither completely understood nor reversible. We estimated population decline based on the wintering population size, but under this criterion, population decline can also be investigated based on levels of exploitation, which could be applicable to Anatidae species as they are regularly hunted in Iran (Balmaki, Behrouzi-Rad \& Barati, 2005; Nourani et al., 2014). However, although there have been attempts to quantify the scale of hunting activities in Iran by means of market investigations (Ashoori, 2008; Balmaki et al., 2005), hunting activities are mostly done illegally and exact figures are difficult to obtain.

While assessing extinction risk under Criterion B (Geographic range restriction), we also encountered various uncertainties in dealing with the data. The distribution maps that we used, although useful for calculation of EOO, were not accurate enough for AOO estimation 
1 for three main reasons. Firstly, these maps are a compilation of records and observations

2 since the 1970s, which might not be representative of the exact distribution of the species

3 today. Secondly, they have much coarser resolution than the recommended $2 \mathrm{~km} \times 2 \mathrm{~km}$

4 reference scale (IUCN, 2011). Although we trialed the application of a scale correction factor

5 (IUCN, 2011; Nourani, Kaboli \& Collen, 2015), we decided against using such estimations in

6 our assessments, due to the original distribution maps not being compiled by thorough and

7 structured investigations throughout the country. We therefore could not ascertain that empty

8 grid cells represented true absences. Jiménez -Alfaro, Draper \& Nogués-Bravo (2011) have

9 suggested the use of presence-only species distribution modelling (SDM) for estimation of

10 AOO in such circumstances. However, they also point to the importance of scale when employing such techniques. With the grid scale of distribution maps in the Atlas of Birds of Iran, the use of SDMs would overestimate the AOOs. Sub-criterion B2 was therefore not used.

Criterion C (small population size and decline) did not lead to classification of any species as threatened. Although sub-criterion C1 was applicable to the study species, it did not lead to any final classification. Criterion D was the only criteria, apart from criterion A, which led to final classification of national populations of Anatidae species.

Although we were able to assess most of the non-breeding populations by addressing the uncertainty in population data, this was not the case with breeding populations. Other than criterion B, other criteria depend on most part on some index of population size or population trend. In the lack of any population data therefore, categorization of species is not very promising. It is common among national Red Listing efforts based on opportunistically collected data to depend on criterion B, due to the lack of population data (Foggi et al., 2015; Raimondo, von Staden \& Donaldson, 2013). To compile effective and objective Red List 
1 assessments under the IUCN categories and criteria, it seems vital to complement the existing

2 opportunistically collected data with data collected in a standardised way. As a first step to enhancing such data collection, we suggest that the limited resources be allocated in structured sampling of species distributions with a suitable design. Coordinating such a project will be less time- and money- consuming compared to surveys for population size estimation, as volunteers with lower level of knowledge and training can participate. These measures will make it possible to assess the species against criterion B based on the current distribution of the species.

Generating further data on distribution of species to aid classification under criterion B should be balanced against the application of modelling techniques to help provide greater insight into risk promoting processes. Relying on risk classification based solely on current geographic range status of species is likely to bias threatened species lists to those species' displaying one symptom of high risk-that of restricted range (Robbirt, Roberts \& Hawkins, 2006). Such data are no doubt useful for the purposes of conservation planning, but risk is also determined by rate of decline, both in population size and geographic distribution (Isaac et al., 2014). We therefore suggest in addition to survey work, distribution modelling techniques are employed for modelling the past distribution of the species, in order to understand medium-term trends. Depending on the time-span needed for calculating trends for each species (ten years or three generations, whichever is longer; IUCN, 2001), environmental explanatory variables necessary for building models of past distributions can be retrieved either from the national organizations (National Cartographic Center and Forests, Range and Watershed Management Organization), or online global databases and analysis of satellite imagery data (e.g. http://landsat.usgs.gov). Doing so could facilitate calculations of trends for $\mathrm{AOO}$ and EOO. Moreover, in order to save time and resources during the initial Red Listing of a large number of species, experiences provided by other practitioners suggest 
1 the assignment of a permanent team for coordinating and conducting Red List assessments

2 within the country (Raimondo et al., 2013) and to use data available for better known species

3 to infer the threat status of other species that share similar distribution and habitats

4 (Brummitt, Bachman \& Moat, 2008; Raimondo et al., 2013).

6 Conclusion

7 Lack of high-quality monitoring data is a problem that many countries wishing to conduct

8 extinction risk assessments have to tackle. Attempts to compile national red species lists have

9 been slowed by such issues. However, collecting data for Red Listing has the added value of aiding the achievement of some of the aims of CBD in reporting the state of biological diversity within countries. We expect that the complications and uncertainties that we faced in Red List assessment at national level in Iran are likely to serve as a case study for the concerns of many national Red List assessors worldwide. By sharing our experiences we hope to provide national Red List assessors an understanding of challenges of working with low quality data, which limits the number of successful categorizations. We urge countries to not depend entirely on opportunistically collected data, but to use it as a base from which to build more structured monitoring schemes. Establishing data collection schemes and optimizing the use of collected data would result in more effective IUCN categories and criteria. Furthermore, although using opportunistically collected data can be very useful in inferring rates of decline for species at certain sites, accounting for and dealing with uncertainty in decision-making requires expert elicitation. To tackle these problems, we urge other national assessors to share their experiences, including monitoring and data collection as well as decision-making strategies under uncertainty, and provide thorough documentation in English and in a fashion that would be usable worldwide. 
2 Acknowledgements

3 We would like to thank Monika Böhm, Arco Van Strien, Stuart Butchart, Roozbeh Behrooz,

4 and Steven Bachman for providing valuable comments and suggestions throughout this study.

5 We are also thankful to Ali Khani for his help with updating the geographic distribution data

6 and personnel of Ornithology Unit of Iran's Department of Environment for providing access

7 to waterbird census archives.

8 
References

2 Akçakaya, H. R., Ferson, S., Burgman, M. A., Keith, D. A., Mace, G. M., Todd, C. R.

3

4 (2000). Making Consistent IUCN Classifications under Uncertainty. Conserv. Biol. $14,1001$.

Anderson, S. (1999). The Lizards of Iran. Contributions to Herpetology 15. New York, USA: Society for the study of Amphibians and Reptiles.

Ashoori, A. (2008). Birds offered for sale in the Langarud market, southwestern Caspian Sea. Podoces 3, 97.

Avery, M., Gibbons, D. W., Porter, R., Tew, T. O. M., Tucker, G. , Williams, G. (1995). Revising the British Red Data List for birds: the biological basis of U.K. conservation priorities. Ibis 137, S232.

Balmaki, B., Behrouzi-Rad, B. , Barati, A. (2005). Survey of determination of hunting rate of migrant waterbirds in Gilan province. J. Environ. Stud. 36, 41.

Bennun, L. A., Njoroge, P. , Pomeroy, D. (2000). Birds to watch: a Red Data List for East Africa. Ostrich 71, 310.

Birdlife International (2004). Birds in Europe: population estimates, trends and conservation status. BirdLife Conservation Series No. 12.

Brito, D., Ambal, R. G., Brooks, T., Silva, N. D., Foster, M., Hao, W., Hilton-Taylor, C., Paglia, A., Rodríguez, J. P. , Rodríguez, J. V. (2010). How similar are national red lists and the IUCN Red List? Biol. Conserv. 143, 1154.

Brummitt, N., Bachman, S. P. , Moat, J. (2008). Applications of the IUCN Red List: towards a global barometer for plant diversity. Endanger. Species Res. 6, 127.

Collen, B., Dulvy, N., Gaston, K., Gärdenfors, U., Keith, D., Punt, A., Regan, H., Böhm, M., Hedges, S., Seddon, M., Butchart, S., Hilton-Taylor, C., Hoffmann, M., Bachman, S. , 
Akçakaya, H. (2016). Clarifying misconceptions of extinction risk assessment with the IUCN Red List. Biol. Lett.

De Grammont, P. C. , Cuarón, A. D. (2006). An Evaluation of Threatened Species Categorization Systems Used on the American Continent. Conserv. Biol. 20, 14.

Eaton, M. A., Gregory, R. D., Noble, D. G., Robinson, J. A., Hughes, J., Procter, D., Brown, A. F. , Gibbons, D. W. (2005). Regional IUCN Red Listing: the Process as Applied to Birds in the United Kingdom. Conserv. Biol. 19, 1557.

Farrier, D., Whelan, R. , Mooney, C. (2007). Threatened species listing as a trigger for conservation action. Environ. Sci. Policy 10, 219.

Foggi, B., Viciani, D., Baldini, R. M., Carta, A. , Guidi, T. (2015). Conservation assessment of the endemic plants of the Tuscan Archipelago, Italy. Oryx 49, 118.

Fox, R., Warren, M. S., Brereton, T. M., Roy, D. B. , Robinson, A. (2011). A new Red List of British butterflies. Insect Conserv. Divers. 4, 159.

Gärdenfors, U., Hilton-Taylor, C., Mace, G. M. , Rodríguez, J. P. (2001). The Application of IUCN Red List Criteria at Regional Levels. Conserv. Biol. 15, 1206.

Gregory, R. D., van Strien, A., Vorisek, P., Gmelig Meyling, A. W., Noble, D. G., Foppen, R. P. B. , Gibbons, D. W. (2005). Developing indicators for European birds. Philos. Trans. R. Soc. Lond., B, Biol. Sci. 360, 269.

Isaac, N. J. B., van Strien, A. J., August, T. A., de Zeeuw, M. P. , Roy, D. B. (2014). Statistics for citizen science: extracting signals of change from noisy ecological data. Method Ecol. Evol. 5, 1052.

IUCN (2001). IUCN Red List categories and criteria: Version 3.1. ii+30 pp. Gland, Switzerland and Cambridge, UK.

IUCN (2003). Guidelines for application of IUCN Red List criteria at regional levels. Version 3.0. ii +26 pp. Gland, Switzerland and Cambridge, UK. 
1 IUCN (2011). Guidelines for using the IUCN Red List categories and criteria. Version 9.0.): Prepared by the Standards and Petitions Subcommittee.

Jiménez-Alfaro, B., Draper, D. , Nogués-Bravo, D. (2012). Modeling the potential area of occupancy at fine resolution may reduce uncertainty in species range estimates. Biol. Conserv. 147, 190.

Joppa, L. N., Butchart, S. H. M., Hoffmann, M., Bachman, S. P., Akçakaya, H. R., Moat, J. F., Böhm, M., Holland, R. A., Newton, A., Polidoro, B. , Hughes, A. (2016). Impact of alternative metrics on estimates of extent of occurrence for extinction risk assessment. Conserv. Biol. 30, 362.

Kaboli, M., Aliabadian, M., Tohidifar, M., Hashemi, A., Roselaar, C. S. (2012). Atlas of Birds of Iran. Tehran, Iran: Iran Department of Environment.

Keller, V., Zbienden, N., Schmid, H. , Volet, B. (2005). A Case Study in Applying the IUCN Regional Guidelines for National Red Lists and Justifications for their Modification. Conserv. Biol. 19, 1827.

Khaleghizadeh, A., Scott, D. A., Tohidifar, M., Musavi, S. B., Ghasemi, M., Sehhatisabet, M. E., Ashoori, A., Khani, A., Bakhtiari, P., Amini, H., Roselaar, C., Ayé, R., Ullman, M., Nezami, B. , Eskandari, F. (2011). Rare birds in Iran in 1980-2010. Podoces 6, 1.

Mace, G. M., Collar, N. J., Gaston, K. J., Hilton-Taylor, C., Akçakaya, H. R., LeaderWilliams, N., Milner-Gulland, E., Stuart, S. N. (2008). Quantification of extinction risk: IUCN's system for classifying threatened species. Conserv. Biol. 22, 1424.

Mace, G. M. , Lande, R. (1991). Assessing Extinction Threats: Toward a Reevaluation of IUCN Threatened Species Categories. Conserv. Biol. 5, 148.

Maes, D., Isaac, N. J. B., Harrower, C. A., Collen, B., van Strien, A. J. , Roy, D. B. (2015). The use of opportunistic data for IUCN Red List assessments. Biol. J. Linn. Soc. 115, 690. 
1 Maes, D., Vanreusel, W., Jacobs, I., Berwaerts, K., Van Dyck, H. (2012). Applying IUCN Red List criteria at a small regional level: A test case with butterflies in Flanders (north Belgium). Biol. Conserv. 145, 258.

Master, L. L. (1991). Assessing Threats and Setting Priorities for Conservation. Conserv. Biol. 5, 559.

Miller, R. M., Rodríguez, J. P., Aniskowicz-Fowler, T., Bambaradeniya, C., Boles, R., Eaton, M. A., Gärdenfors, U., Keller, V., Molur, S. , Walker, S. (2006). Extinction risk and conservation priorities. Science 313, 441.

Miller, R. M., RodríGuez, J. P., Aniskowicz-Fowler, T., Bambaradeniya, C., Boles, R., Eaton, M. A., GÄRdenfors, U. L. F., Keller, V., Molur, S., Walker, S. , Pollock, C. (2007). National Threatened Species Listing Based on IUCN Criteria and Regional Guidelines: Current Status and Future Perspectives. Conserv. Biol. 21, 684.

Milner-Gulland, E. J., Kreuzberg-Mukhina, E., Grebot, B., Ling, S., Bykova, E., Abdusalamov, I., Bekenov, A., GÃrdenfors, U., Hilton-Taylor, C., Salnikov, V. , Stogova, L. (2006). Application of IUCN Red Listing Criteria at the Regional and National Levels: A Case Study from Central Asia. Biodivers. Conserv. 15, 1873.

Moraes, M., Borges, R., Martins, E., Fernandes, R., Messina, T. , Martinelli, G. (2014). Categorizing threatened species: an analysis of the Red List of the flora of Brazil. Oryx 48, 258.

Nascimbene, J., Nimis, P. L. , Ravera, S. (2013). Evaluating the conservation status of epiphytic lichens of Italy: A red list. Plant Biosyst. 147, 898.

Nourani, E., Kaboli, M. , Collen, B. (2014). An assessment of threats to Anatidae in Iran. Bird Conserv. Int. 25, 242. 
1 Nourani, E., Kaboli, M. , Collen, B. (2015). The role of geographic range metrics in determining national threat status of species; a case study of Anatidae in Iran. $J$ Nat Env 68, 293 [in Persian with English summary].

Pannkoek, J. , van Strien, A. (2005). TRIM 3 Manual (Trends and Indices for Monitoring data). Voorburg, The Netherlands.

Raimondo, D. C., von Staden, L. , Donaldson, J. S. (2013). Lessons from the Conservation Assessment of the South African Megaflora 1. Ann. Mo. Bot. Gard. 99, 221.

Rankou, H., Culham, A., Sghir Taleb, M., Ouhammou, A., Martin, G., Jury, S. L. (2015). Conservation assessments and Red Listing of the endemic Moroccan flora (monocotyledons). Bot. J. Linn. Soc. 177, 504.

Reed, J. (1992). A system for ranking conservation priorities for Neotropical migrant birds based on relative susceptibility to extinction. In Ecology and Conservation of Neotropical Migrant Landbirds. Hangan, J. M. , Johnston, D. W. (Eds.). Washington, D.C. USA: Smithsonian Institution Press.

Robbirt, K., Roberts, D. , Hawkins, J. (2006). Comparing IUCN and Probabilistic Assessments of Threat: Do IUCN Red List Criteria Conflate Rarity and Threat? Biodivers. Conserv. 15, 1903.

Scott, D. A. (2010). Results of mid-winter waterbird counts in Iran in the early 1970s. Podoces 5, 11.

Scott, D. A. , Rose, P. M. (1996). Atlas of Anatidae populations in Africa and western Eurasia. Wageningen: Wetlands International.

Secretariat of the Convention on Biological Diversity (2005). Handbook of the Convention on Biological Diversity Including its Cartagena Protocol on Biosafety, 3rd edition. Montreal, Canada. 
1 Stojanović, D., Ćurčić, S., Curčić, B. M. , Makarov, S. (2013). The application of IUCN Red List criteria to assess the conservation status of moths at the regional level: a case of provisional Red List of Noctuidae (Lepidoptera) in Serbia. J. Insect Conserv. 17, 451.

Townsend, A., de Lange, P., Duffy, C., Miskelly, C., Molloy, J. , Norton, D. (2008). New Zealand threat classification system manual: Science \& Technical Publishing, Department of Conservation.

Van Strien, A., Pannekoek, J., Hagemeijer, W. , Verstrael, T. (2004). A loglinear Poisson regression method to analyse bird monitoring data. In Bird Numbers 1995, Proceedings of the International Conference and

13th Meeting of the European Bird Census Council: 33-39. Anselin, A. (Ed.). Pärnu, Estonia: Bird Census News 13.

Warren, M. S., Barnett, L. K., Gibbons, D. W. , Avery, M. I. (1997). Assessing national conservation priorities: an improved red list of British butterflies. Biol. Conserv. 82, 317.

Wetlands International (2012). Waterbird Population Estimates, Fifth Edition. Summary Report. Wegeningen, The Netherlands.

Zamin, T. J., Baillie, J. E., Miller, R. M., Rodríguez, J. P., Ardid, A., Collen, B. (2010). National red listing beyond the 2010 target. Conserv. Biol. 24, 1012. 